\title{
Marginal Abatement Cost Curves (MACCs): Important Approaches to Obtain (Firm and Sector) Greenhouse Gases (GHGs) Reduction
}

\author{
Ali Ahmed Ali Almihoub ${ }^{1}$, Joseph M. Mula ${ }^{1} \&$ Mohammad Mafizur Rahman ${ }^{1}$ \\ ${ }^{1}$ School of Accounting, Economics and Finance, Faculty of Business and Law, University of Southern \\ Queensland, Australia \\ Correspondence: Ali Ahmed Ali Almihoub, School of Accounting, Economics and Finance, Faculty of Business \\ and Law, University of Southern Queensland, Australia. Tel: 61-43-419-5770. E-mail: ali.almihoub@usq.edu.au
}

Received: December 31, 2012

Accepted: March 21, 2013

Online Published: April 18, 2013

doi:10.5539/ijef.v5n5p35

URL: http://dx.doi.org/10.5539/ijef.v5n5p35

\begin{abstract}
The study aims to identify appropriate methods that can help organisations to reduce energy use and emissions by using an effective concept of sustainability. In different countries, estimates of marginal abatement costs for reducing GHG emissions have been widely used. Around the world, many researchers have focused on MACCs and reported different results. This may due to different assumptions used which in turn lead to uncertainty and inaccuracy. Under these circumstances, much attention has been paid to the need for the role of MACC in providing reliable information to decision makers and various stakeholders. By reviewing the literature, this paper has analysed MACCs in terms of the role of different approaches to MACCs, representations of MACCs, MACC applications, pricing carbon, verification, and sectors analysis for energy and emissions projections. This paper concludes that MACCs should depend on actual data to provide more reliable information that may assist (firms and sectors) stockholders to determine what appropriate method for reducing emission.
\end{abstract}

Keywords: marginal abatement cost curves (MACCs), different approaches to MACCs, representations of MACCs, MACC applications, pricing carbon, verification, and sectors analysis

\section{Introducing Marginal Abatement Cost Curves}

Marginal cost (MC) is the change in total costs that arises when the quantity produced changes by one unit. In other words, the $\mathrm{MC}$ of an additional unit of output is the cost of the additional input needed to produce that output. More precisely, marginal cost is the derivative of total production costs with respect to the level of output (Sullivan \& Sheffrin, 2003). The MC approach is defined as the first derivative of the cost as a function of energy conservation or for practical causes; additional costs are compared to the benefits to define efficiency levels (Jakob, 2006). It is also called incremental cost.

Narrowing the definition to abatement costs, enterprise cost explains the cost of an individual abatement alternative, which is assumed to have no large indirect economic impacts on markets and prices (Ekins, Kesicki, \& Smith, 2011). It takes into account such things as the change of techniques in production factories, enhancement of efficiency, fuel switching, or the achievement of infrastructure changes. Cost measurement contains investment, operation, upkeep, and fuel costs as well as disposal (Hutton, Haller, \& Bartram, 2007). In the technology cost accounts, a technology that has many implementations in diverse enterprises takes learning curves into account as well as associated efficiencies and economies of scale (Ekins et al., 2011).

Typically abatement cost data is collected at a micro-economic level and illustrates the costs of technical options for reducing a certain kind of pollution (Schwarzenegger, 2005). They are presented as cost functions (abatement cost curves). Such cost functions plot, for each kind of measure, the cost per unit of avoided pollutant against the volume of avoided pollutants. In applying such curves they mostly confirm the standard economic hypothesis of increasing marginal costs (Faber et al., 2011). However, exceptions mostly exist. In studies of $\mathrm{CO}_{2}$ abatement costs it is often found that significant primary reductions can be obtained as negative costs (net savings), for example by applying energy reduction measures that will enhance profitability (UN, 2003).

Emission scenarios give an indication of possible effects of mitigation policies (Van Vuuren et al., 2008). Emissions scenarios for climate change investigations are not anticipatory or predictive but reflect expert judgments regarding plausible future emissions depending on research into socioeconomic, environmental, and 
technological trends represented in integrated assessment models (Moss et al., 2010). Industrial activities into pollution abatement capital expenditures and operating costs may include more than one of these categories of activities-treatment, recycling, disposal, and pollution prevention; and by three types-air emissions, water discharges, and solid wastes (Gallaher, Morgan, \& Shadbegian, 2008). Thus, abatement cost, accurate data collection, emissions scenarios and their applications are of critical importance in emission reduction strategies development. Consequently, a contemporary marginal cost approach can be applied in the form of a marginal abatement cost curve.

Marginal Abatement Cost Curve (MACC) is a function that shows the cost in terms of dollars per unit tonne of GHGs, which is associated with the final unit of reduced emission (Kuik, Brander, \& Tol, 2009). This last unit of emission abatement is measured in amounts of $\mathrm{CO}_{2}$ equivalents reduced. Just as the name suggests, a MACC enables one to analyse the cost of the final abated amount of carbon dioxide as well as reveal the total costs associated with $\mathrm{CO}_{2}$ abatement by integrating the whole cost curve (van Odijk, Mol, Harmsen, Struker, \& Jacobs, 2012). According to the Environmental Protection Agency (2008, p. 10):

The marginal abatement cost curve is an evidence-based tool available to policy makers to assess the potential for greenhouse gas abatement in a region and/ or sector of the economy according to the cost of abatement. It is derived by generating expectations about the potential for abatement relative to a reference case. Construction of the marginal abatement cost curve involves assessing individual initiatives for their abatement potential and cost, and arranging these initiatives in graphical format from least cost to highest cost order. Importantly, the profile of initiatives considered is crucial: invoking some abatement options will impact the abatement potential and costs of others (for example, improvements in electricity efficiency in consumption will reduce the abatement potential of electricity supply initiatives).

A MACC meta analysis was undertaken of up-to-date studies into costs of GHGs alleviation policies. It found that marginal abatement costs of tough long-term targets that were considered by the European Commission are frozen and very uncertain but may surpass costs that have been suggested by present policy assessments (Kuik et al., 2009). McKinsey (2007a) has developed MACCs for the international economy and for several countries including Australia, the USA, the UK, and Germany (Hardisty, 2009). In addition, the concept of a MACC is an approach available to an economy to achieve increasing levels of emission reductions. These are valuable tools in understanding emissions trading, driving forecasts of carbon allowance prices, prioritizing investment opportunities, and shaping policy discussions. However, there are a number of approaches to creating MACCs.

\section{Different Approaches to MACCs}

MACCs can be determined in many ways. First of all, expert-based approaches are developed from experts' assumptions, which are derived from the respective costs of abatement measures, the creation of $\mathrm{CO}_{2}$ emissions and the potential of abatement measures in reducing $\mathrm{CO}_{2}$ emissions. For instance, the cost of abatement measures like incorporation of new technologies, improvements in efficiencies as well as fuel switch can be considered using this approach (Kesicki, 2010c). Based on the various assumptions made, abatement measures are openly arranged from the cheapest to the most expensive. With this arrangement, there is an explicit representation of the associated costs of reducing additional emissions (Hogg, , Ballinger, \& Elliot, 2008).

In 1970, the concept of an expert-based approach was initially employed in reducing industrial consumption of electricity and crude oil (Kesicki, 2010a). In recent years, this MACC approach has attracted a great deal of attention due to national studies published by McKinsey \& Company (Kesicki, 2010b). McKinsey \& Company managed to develop two expert-based curves-countries based and global. Through the process of differentiation, expert-based curves can estimate abatement curves. However, this highly relies on discount rates, subsidies as well as taxes. To reflect the societal perspectives in abatement measures over a specific period of time, reduced discount rates (i.e. 3.5\%) are normally used (Pye et al., 2008). However, these abatement cost curves normally consider higher rates of interest, taxes, and subsidies in order to come up with the right measure of costs associated with investment decisions. Similarly, there is integration of specific discount rates associated with higher technologies (Kesicki \& Strachan, 2011). A MACC could reveal financial constraints that face households as well as the uncertainties that can be linked to investment decisions geared towards reducing the cost of GHG emissions (Kockelman, Bomberg, Thompson, Whitehead, \& Traveled, 2009).

One major advantage of this MACC approach is that it offers a great deal of ease in understanding it (van Odijk et al., 2012). Generally, its marginal costs as well as abatement potential of various measures can be linked to a single mitigation option without any ambiguity. In addition, technological details that are considered in this approach can be extensive (Wang, Wang, \& Chen, 2009). However, this will depend on improvements from studies (De Vries, van Vuuren, \& Hoogwijk, 2007). Basically, a MACC developed using an expert-based 
approach reveals the technological capacity of measures used in abating GHG emissions (Watkiss \& Hunt, 2011). Since MACCs developed using this approach highly depend on technical judgments, their assessments require integration of technology-specific subsidy distortions as well as existing taxes (Kesicki, 2010b). Nonetheless, a MACC developed using this approach does not take into account behavioural aspects as well as barriers associated with an institution and its implementation. As a result, this seems to leave this approach with higher abatement potentials compared to other approaches. By improving energy efficiency, it is argued that behavioural aspects are sometimes catered for by "adjusting the reference demand" (Kesicki, 2010a, p. 5).

Based on the concept of 'probability of realization,' a technology-based approach can exclude promising technologies from the future since it primarily focuses on commonly existing technologies. Similarly, this MACC approach makes it impossible to have an accumulated abatement cost from various sectors like transport, residential, and industrial that contribute to GHG emissions (Legge \& Scott, 2009). This difficulty is quite common due to the fact that mitigation costs are usually implemented by different experts (decision-makers) with different perspectives. In addition, baseline assumptions in this approach have possibilities of high inconsistencies as different experts may have different references to support their perspectives. It implies that for proper calculation of marginal costs associated with abatement potential, a reference aspect of the development must be considered (Murphy \& Jaccard, 2011). However, only those that could offer cheaper abatement potentials should be adopted. Most significant in this MACC approach is non-consideration of various interaction types. It should be noted that MACCs developed by this approach cannot capture interactions that occur between behavioural aspects, economy, and abatement measures. On the other hand, there is a possibility of reducing the abatement cost due to the effects of technology learning that occurs before and after a given period of time considered in a MACC (Kesicki, 2010b). Moreover, this approach presents many difficulties in assessing single-based measures.

A Model-Derived MACC approach is another widely used method (Watkiss \& Hunt, 2011). This approach uses various energy models and techniques. In this respect, two major MACC models derived are top-down models and bottom-up models, the former being economy-oriented while the latter is engineering-oriented (Kesicki, 2010c). Historically, policy-makers have encountered many difficulties when they were choosing between models for evaluation of policies to influence the technology choices of energy-related intervention (Jaccard, Nyboer, Bataille, \& Sadownik, 2003).

An abatement curve is developed in both bottom-up and top-down models by summarising the price of GHG emissions $\left(\mathrm{CO}_{2}\right)$. This carbon price can result from either of the two sources: "runs with different strict emission limits" or from the GHG emissions coming from various carbon dioxide prices (Kesicki, 2010a, p. 6). Unlike the expert-based MACC approach, the model-based abatement curve does not consider or show any technical information. The bottom-up approach is highly dependent on technological information. Bottom-up models present how changes in energy efficiency, fuel, and emissions control tools may impact infrastructure and energy use, consequently environmental impacts (S. Morris, Goldstein, \& Fthenakis, 2002).

It is generally assumed that technologies that provide energy services themselves are perfect substitutes except for the differences in the expected financial costs, energy use, and emissions. When financial costs are converted in different time periods to present value using a social discount rate, many of the techniques available appear to be profitable or relatively, just a little more expensive than the existing stocks of equipment and buildings. Bottom-up models appear in many cases as a useful method, which can be profitable or improve the environment at a low cost if these low-emission technologies were to achieve market dominance (Bailie, Bernow, Dougherty, \& Goldberg, 2009). Traditional bottom-up models are partial equilibrium models with a focus on optimization of costs in the energy sector or sub-sector specifically, but dispense with links between these sectors and the wider economy (Kanudia \& Loulou, 1999).

A bottom-up model sometimes exhibits lower MACC values compared to a top-down approach due to the fact that the approach does not incorporate feedback impacts from both macro- and micro-economic elements (Pye et al., 2008). Other than the model's structure, this approach is associated with assumptions on key economic drivers like technology transfer, disaggregation (sectoral and regional), emission levels and trade across borders (Böhringer \& Rutherford, 2008). Apart from the aforementioned weaknesses, it should be remembered that a MACC derived from a bottom-up approach has direct abatement costs, highly risks facing penny-switching, where minor changes in costs lead to large shifts in the energy system, and does not consider rebound impacts of abatement measures (Kesicki, 2010b). This highly contrasts with top-down models that try to consider internal economic reactions in the entire economy (Böhringer \& Rutherford, 2008). Logically, this would give limited information on how the economy could be in the future. Based on this fact, a MACC based on a bottom-up approach would be quite inefficient in revealing the actual marginal abatement cost, thus bringing an accusation 
of overestimating the core elements of a MACC. One example of a MACC developed from the concept of a bottom-up model is Targets Image Energy Regional (TIMER). Its features support of bottom-up models to yield a MACC with a balanced level of aggregation and concentrates on dynamic energy issues like fossil-fuel depletion, inertia, trade and learning by doing (Kesicki, 2010b). Not only do bottom-up models have a place in energy and emissions reductions but also top-down models are considered important.

Alternatively, a top-down analysis estimates total relationships between relative costs and market shares of energy and other inputs for the economy linked to economic sectoral and macro output in a wider context for balance. From the top-down model, the estimated parameters characterise the response of the model to the policy, including the elasticity of substitution and improved efficiency of energy use in autonomous areas. Also it can estimate historical data, if the previous data is available. If the historical data is not available, estimations can be obtained from other sources (Bataille, Jaccard, Nyboer, \& Rivers, 2006). The top-down model estimates parameters of real market data, with higher energy prices and consumption change from a historical perspective; they are supposed to reveal the actual preferences of consumers and businesses. Because they require technological details, they have restricted the top-down models of simulation in fiscal policies, which increase the relative cost of inputs to a particular share. The necessary signal to achieve the fiscal target for reducing emissions is due to the cost implied. This includes intangible costs related to risks of new technologies and risks of long-recovery technology. Preferences for the attributes of one technology over its rival are also very important for any emissions reduction. Thus, estimates of cost to achieve environmental goals using the top-down models are usually higher and almost never less than a bottom-up estimate (Rivers \& Jaccard, 2006).

The top-down approach is also subject to criticism because it might not be useful for policy makers (Chattopadhyay, 2010). If the top-down approach produces parameters for the imaging of technological change, the elasticity of substitution and autonomous energy efficiency improvement is the amount of data compiled historically. There is no guarantee that these parameter values will still be valid in the future under different policies to improve the environment (Grubb, Köhler, \& Anderson, 2002). Growing concern with this issue has led to some top-down models exploring methods of treatment of technological change using the bottom-up approach. But, as of yet there has been little success in linking real-world evidence to estimations of parameters of technological change in these models (Löschel, 2002). Other difficulties are restrictions imposed on the development of policy-makers understanding of technology as well as policies in the form of specifically building tax exemptions, subsidies, regulations, and media programs (Kesicki, 2010a). Because traditional top-down models represent technological change as a phenomenon, the overall abstract, this approach only helps policy makers to assess the level of fiscal policies on the economy such as taxes and tradable permits.

Top-down models capture government details, supply levels of inputs, end users, product flows, producing sectors, money as well as services that exist in the entire economy (Böhringer \& Rutherford, 2008). It can thus be seen as a model with an equilibrium approach to MACC development since it integrates economic data in establishing numeric values of final prices that would influence both demand and supply. Unlike bottom-up approaches, top-down models are commonly used for computations of MACCs (Böhringer \& Rutherford, 2008). The use of these two approaches ensures that interactions that occur between abatement measures are significantly considered. It is also possible for one approach to compliment the inconsistencies exhibited in the other since they adopt a system's approach in generating a MACC (Böhringer \& Rutherford, 2008). As a result, this makes bottom-up and top-down approaches powerful MACC approaches that reveal uncertainty associated with various abatement measures (Jackson, 1991).

While it is impossible for any model of policy to be completely accurate in its representation of the current circumstances or description of the dynamics of the future, the above discussion refers to standards that can judge the ability of the model to be more useful for policy makers seeking to induce technological change (Rivers \& Jaccard, 2006). Policy-makers require models that can be a realistic assessment of combined effects of policies ranging from the economy to broad technology-specific measures (Metcalfe, 1995). Thus instruments will include the potential for command and control systems, as well as financial charges and subsidies (Stavins, 2007). To do so, models should include a clear representation of technologies that compete to provide services in all economic sectors. Also, they should mimic the way in which consumers, companies, and producers choose between these techniques to reflect the close balance and feedback in the real world. These could achieve balance between energy and technology overall structure and performance of the economy (Tester, 2005).

Since none of the traditional models (bottom-up or top-down) are good performers in relation to these standards, efforts have been made to develop a hybrid that combines the essential elements of both models (Murphy, Rivers, \& Jaccard, 2007; Schaefer \& Jacoby, 2005). Thus, some models integrate supply and demand for energy, and even include some of the interactions between the energy system and economy as a whole. Developments 
with the optimal model MARKAL is worth considering. MARKAL is applied on a large scale from bottom-up, dynamic, and originally mostly linear programming model developed by the Energy Technology Systems Analysis for International Energy Agency (Schaefer \& Jacoby, 2005). As a result, it has contributed to this framework of models for energy planning, national and local, and developed strategies for carbon mitigation (Nystrom \& Wene, 1999; Seebregts, Goldstein, \& Smekens, 2001; Worrell, Ramesohl, \& Boyd, 2004). There is a new type of this form called SAGE (new MARKAL) for a degree of behavioural realism in the process of technology acquisition (Murphy et al., 2007) by consumers, producers and modelling, also myopia, and including the representation of non-monetary costs that affect behaviour. On the other hand, some models include technical details, mostly in the energy supply sector (Bohringer \& Loschel, 2006), although others have made greater progress in their representation, including more details of other sectors (Schafer \& Jacoby, 2006). Unlike in the expert-based approach, model-based approaches present little complications in combining various abatement curves from different sectors (Böhringer \& Rutherford, 2008), due to their reliance on societal perspectives. It is therefore concluded that a majority of expert-based weaknesses are addressed by model-driven approaches, and could be a useful methodology to develop a MACC, but the question of how to represent complex models and their output to decision makers is still a challenge.

\section{Representations of MACCs}

MACCs are becoming a standard tool for analysing price and number effects in carbon markets and are broadly used, for example, for analysing the integration of national trading systems (Anger, 2008; Criqui, Mima, \& Viguier, 1999; Ellerman \& Decaux, 1998 ; Stankeviciute, Kitous, \& Criqui, 2008). MACCs can be derived in numerous ways which are reflected in the differences across models (Flachsland, Brunner, Edenhofer, \& Creutzig, 2011). According to McKinsey \& Company (2010a), the representation of a MAC-curve can be in the form of a bar chart or curve. Graphs can be positive or can exhibit negative and positive values. However, whichever representation method is used, there is little difficulty in reading them. For instance, in a bar chart every bar represents one option towards low carbon emissions with its width representing the abatement capacity relative to business as usual (BAU). The height of every bar also reveals the cost of abatement options, relative to BAU. In either line graph or bar chart, this cost is expressed in dollars/Euros/Cedis per unit tonne of GHG emission controlled or avoided. However, the sum of all bar-widths reveals the total abatement potential while their total area reveals the marginal costs for the chosen direction such as in Figures 1,2 and 3. Bar charts are now more commonly used even though the method is still referred to as a MAC curve.

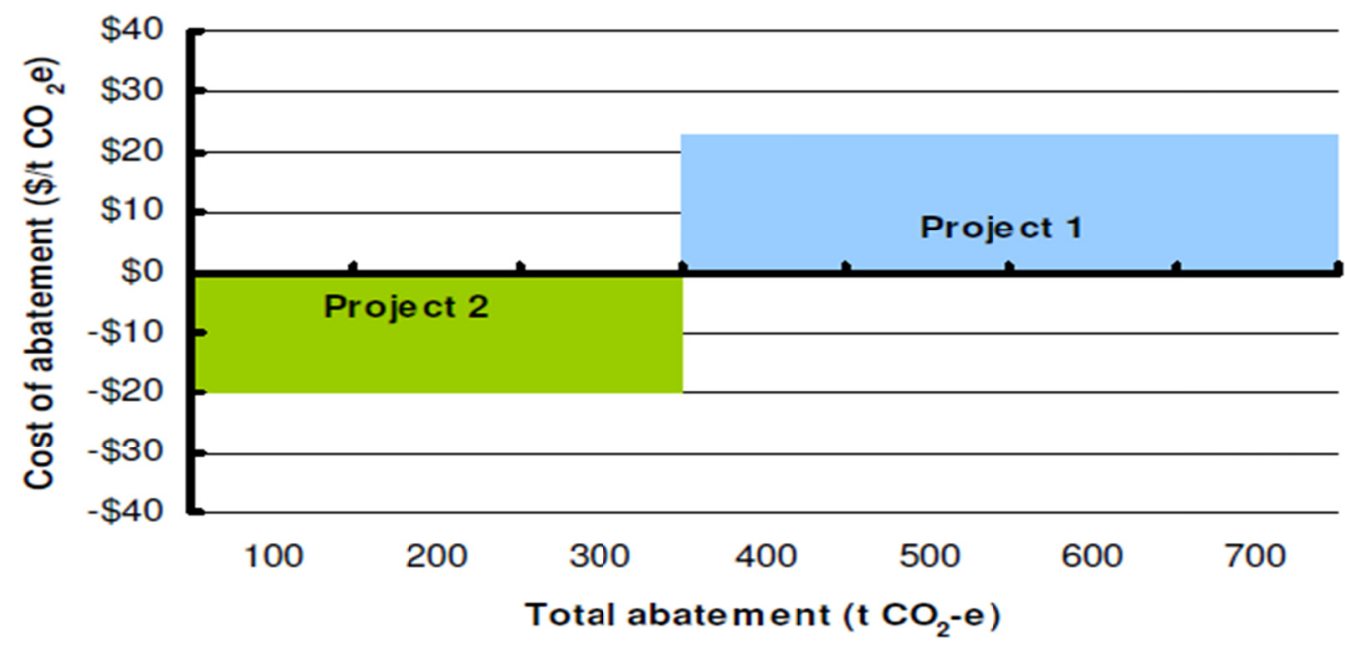

Figure 1. MACC for two projects 


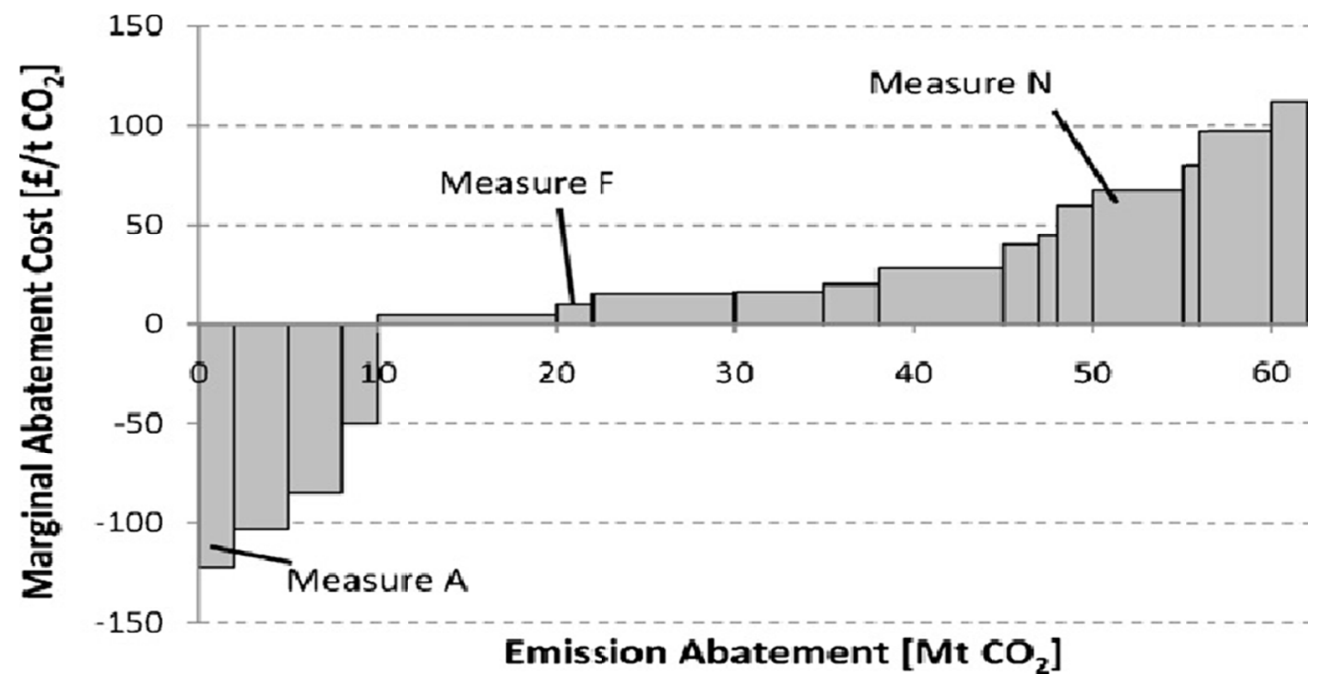

Figure 2. Sample marginal abatement cost curve (Kesicki \& Strachan, 2011)

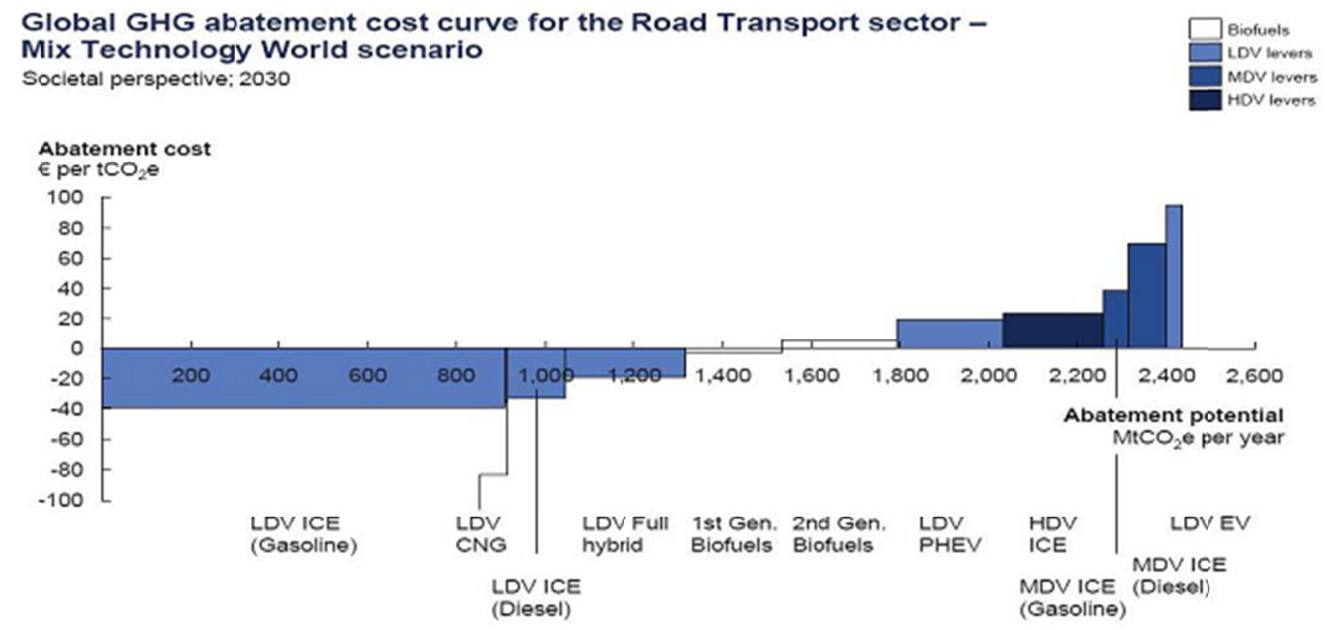

Figure 3. Global GHG MACC for transportation (Powell, 2011)

\section{MACC Applications}

MACCs have been applied by a number of researchers. Many economists, research institutes, and consultancies have produced MACCs. Bloomberg New Energy Finance (Turner, G, Sjardin, M, \& Capua, M. D, 2010) and McKinsey \& Company (2007a) have produced broad economy analyses of GHGs reductions for the United States. ICF International (Schwarzenegger, 2005) produced a California specific curve following AB-32 legislation (Sweeney \& Weyant, 2008). The US Environmental Protection Agency has done work on a MACC for non-carbon dioxide emissions. Enter data and LEPII-CNRS (France) produced MACCs with the POLES model for the 6 Kyoto Protocol gases. These curves have been used by various public and private actors to assess carbon policies (Turner. G et al., 2010).

Normally, MACCs cover emissions reduction opportunities across some sectors in an economy including power, industry, waste, buildings, agriculture, transport, and forestry. In the UK, MACCs have been widely used in both domestic and international environments in shaping climate change policies (DECC, 2009). This implies that these curves have played a significant role in helping policy makers. In connection to this, the Committee on Climate Change, which was initiated to guide the UK on abating greenhouse effects, came up with MACCs that found various applications in different areas. In this regard, the UK government used the concept of a MACC to introduce a carbon tax that aimed at abating the use of fossil fuels in agricultural, commercial, and industrial 
sectors (DECC, 2009). Since their establishment, the use of MACCs has spread to quite a number of countries, which use them to evaluate their climatic policies. For instance, this has been realized in France where model-based MACCs significantly contributed to the preliminary steps in evaluating abatement measures. Based on these curves, quota systems, renewable obligation and feed-in policies have been introduced to control the deployment process of technologies associated with the generation of electricity. However, it is reported that the majority of MACCs being used in the UK are technology-based (bottom-up).

Economically, MACCs have been used by the UK government to guide the potential of technical mitigations for energy (Markets, 2010). It also uses these curves to forecast the future of energy sectors in terms of its cost elements. Another economic application of MACCs is by carbon traders who use it to derive the supply function, which helps in modelling the fundamentals of carbon prices. Based on the decision making properties of MACCs, power companies have applied these concepts in guiding their long-term investment decisions based on the different efficiencies offered by generation choices of abatement measures (Smith et al., 2007). In recent work by McKinsey \& Company (2007), it was realized that MACCs have been widely applied to evaluate how greenhouse gas emissions can be reduced.

Nowadays, MACCs have improved as a standard instrument to analyse the impacts of the Kyoto Protocol and emissions trading (Ellerman \& Decaux, 1998 ; Wassmann \& Pathak, 2007). The idea of a MACC has come from a company or factory level model of reducing emissions, but it is regularly used for assessing reduction costs for individual sectors of the economy as well as certain regions (Klepper \& Peterson, 2004). Given (a) emissions of unwanted materials and (b) the availability of pollution control technology, use of marginal costs (shadow prices) to achieve a specific goal given a certain emission level of production is increasing (McKitrick, 1999). Apart from technological adaptation there may also be structural changes that can overcome obstacles to emissions reduction. Many firms have used MACCs instead of net present value (NPV), which determines the present value of net costs by summing the discounted cash flows over the life of the option or project. MACCs present a complete picture of environmental costs and benefits, each option over the lifetime of capital employed (Jorge, Fabio P, Genice A, \& O., 2005). To exploit more and get further benefits of using MACC, the following section examines explicit carbon pricing policy regimes that are currently in place.

\section{Pricing Carbon}

Mitigation risk could be driven by growing pressure from all society segments. Domestic and international efforts may attempt to prevent the worst damage caused by climate change such as significant reductions in emissions of GHGs (Sandor, Bettelheim, \& Swingland, 2002). Reductions in emissions are a massive challenge. According to IPCC (2007c), Stern (2007), Garnaut (2008), and Hardisty (2009) there is a globally need to decarbonise by up 60 to 80 per cent by the year 2050, to give business a reasonable opportunity to avoid the worst effects of climate change. The size of this change means that it will put appropriate price signals in the right place to gradually increase the cost of carbon. Management provided by carbon tax on a large scale in one form or another is the main challenge for policymakers at all levels, in all sorts of businesses. Carbon-intensive processes will need to make deep changes to avoid large increases in costs, after-effects on competitiveness, profitability and organizational sustainability (Sandor et al., 2002). Providing a 'cap and trade' scheme also means that overall emissions are limited in preventing the expansion and growth in emissions (Parker, 2009). Thus organizations of all kinds have to develop strategies for growth and expansion of their operation within this new frontier.

Including management of carbon in the process of effective decision-making requires that there is a given carbon price (CP). CP can be embedded in the price during financial and economic analyses of projects; these are used to understand current and future effects of different investment decisions on capital (Hardisty, 2009). However, there are many different methods to consider when evaluating carbon. One such method is market-based prices, which set plans for various trading, social value of the real damage of each additional tonne of GHG emissions emitted, by costing of the shade, and marginal costing of controlling pollution (Shobe \& Burtraw, 2012). Because of their importance each method will be considered in turn.

There are many kinds of emission reduction prices related to each domestic area that depend on different types of mitigation practices (Lee, Zhou, Jung, Wisniewski, \& Sathaye, 1996). Carbon pricing, in one form or another soon became common. In Europe, the prosperity of the carbon market was worth over US\$ 24 billion in 2007, handling more than one billion tonnes equivalent of $\mathrm{CO}_{2}\left(\mathrm{tCO}_{2} \mathrm{e}\right)$. The trading system in the European Union (emissions trading system) long-term stage was 2 average price and predicted to be about US\$20-25/tCO $\mathrm{C}$ (Hardisty, 2009). Clean Development Mechanism (CDM) which was established under the Kyoto Protocol, traded more $\mathrm{CO}_{2}$ equivalents in 2006, and valued at more than US\$15 billion (Hamilton, Bayon, Turner, \& 
Higgins, 2007). Other trading schemes, voluntary and orderly, began to appear all over the world (Hardisty, 2009). In Alberta, Canada's oil and gas-producing province, home of the huge Athabasca tar sands reserves, the Canadian government announced there will be a new tax just on GHG exceeding mandatory reduction targets that is $\$ 15 /$ tonne (Aldy \& Stavins, 2012 ; Hardisty, 2009). Voluntary Chicago Climate Exchange has increased year after year since its inception. The Montreal Stock Exchange announced a similar voluntary market in Canada (Hardisty, 2009). Carbon prices paid are also reducing carbon with mandatory renewable energy targets (MRETs) being developed by various governments around the world, national states, and at local levels (Kuwahata \& Monroy, 2011).While many USA states have their own major goals for renewable energy in place, full participation by the United States at the federal level could have a resounding impact on the way the rest of the planet approaches organizing carbon reduction in the next decades (Hardisty, 2009; Speth, 2009). Australian has set maximum GHGs thanks to the State and Commonwealth Governments MRETs, which started in 2010 (Jotzo \& Betz, 2009). All of these measures impose increasing penalties in terms of direct financial cost to firms that emit large amounts of GHGs.

Although most of the global communities agree to reduce carbon emissions (Nordhaus \& Yang, 1996), there is a significant difference in carbon price between the current market-based systems (in the case of cap-and-trade) and carbon tax rates on the basis of real value of the damage caused by carbon emissions in the atmosphere (Metcalf, 2009). The social cost of carbon reflects the value of the damage caused by each additional tonne of GHG emissions that is put in the atmosphere. These impacts are in terms of the likely effects expected on the global economy caused by global warming, sea level rise, and weather-related events decline in agricultural production, loss of biodiversity, and others (Hardisty, 2009; N. Stern, 2008). Carbon markets or taxes reflect only the cost of government policies that are imposed on emitters. This cost is likely to represent only a fraction of the true value of the damage (Metcalf, 2009). Because emissions are linked to rising temperatures from atmospheric concentrations of GHGs, these gases are long-term. Thus, the total amount of GHGs in the atmosphere are directly related to the social cost of carbon, even to the extent that the higher the concentrations, the higher the social cost of carbon (N. Stern, 2008).

It is important to see the effects of climate change on communities and present strategies to deal with these effects (Wilkinson et al., 2009). N. H. Stern (2007) examines the economic effects on a community using expected impacts of climate change at the macroeconomic level. He has estimated what it would cost to take action to stabilize levels of GHGs in $\mathrm{CO}_{2} \mathrm{e}$ less than $550 \mathrm{ppm}$ (Hepburn \& Stern, 2008). To give the world a chance to avoid high temperatures above about $2^{\circ} \mathrm{C}$, on average, it would cost about 1 per cent of global GDP each year (N. Stern, 2008; Wilkinson et al., 2009). However, not acting to control the emissions, in other words to continue business as usual emissions path, will cost the global economy between 5 and 20 per cent of global output now and forever. Therefore, the fight against climate change is a strategy of pro-growth (Hardisty, 2009).

Although emission reduction can boost profits, an increase in costing can have a negative effect on business (Smale, Hartley, Hepburn, Ward, \& Grubb, 2006). N. H. Stern (2007) does not address exactly how these results affect long-term business, investment decisions and business planning. Climate changes form risks, uncertainties and many opportunities for business, as society increasingly demands to organise work and decrease emissions of GHGs. If this takes the form of mandated goals that reduce carbon and market structures associated with them, some form of carbon tax is needed to be studied carefully and have clear economic value (Hardisty, 2009). Costs and benefits from actions taken by companies to reduce emissions also need to be studied carefully as the cost of the carbon market (now in the order of US\$5-25/tCO (2007) estimates at US\$85/tCO $\mathrm{tCO}_{2} \mathrm{e}$, to get on the path of emissions as 'business as usual'. It is worth mentioning, in addition to that, since the publication of the Stern Review, world GHG emissions have accelerated significantly (International Energy Agency, 2007), proposing that a similar analysis of the social cost of carbon made today will result in higher social cost of carbon.

A shadow price of carbon and social discount rate could be used to evaluate some environmental projects (Hanley, 1992). The United Kingdom's Government identified the Shadow Price of Carbon (SPC) as one of the options to assess projects within the UK (DEFRA 2008). SPC is based on the realisation that one nation cannot be isolated in determining the course of global emissions. Based on the stability of global concentration of $\mathrm{CO}_{2}$ in the atmosphere at $550 \mathrm{ppm}, \mathrm{N}$. H. Stern (2007) calculated implicit social cost of carbon in the USA of $\$ 30 / \mathrm{tCO}_{2}$ e. DEFRA (2003) developed a strategy to achieve stability in the United Kingdom at $550 \mathrm{ppm}$ at a carbon price under US\$50/tCO 2 e, an increase of 2 per cent per year starting in 2007. HM Treasury indicated that a standard social discount rate of 3.5 per cent could be applied (Guo, Hepburn, Tol, \& Anthoff, 2006; Scarborough, 2011).

There is another method to express the cost of carbon which is by using marginal abatement cost (Hardisty, 
2009; J. Morris, Paltsev, \& Reilly, 2008). MAC differs from market price for carbon which is determined directly or indirectly through public policy objectives. Based on the MAC, there is a cost of technological measures and processes to eliminate or reduce emissions (Enkvist, Nauclér, \& Rosander, 2007). An actual carbon price signal might realise important mitigation potential in all sectors (IPCC, 2007c). Although carbon pricing is difficult to control, it is worth considering how it could affect efforts to reduce emissions of GHGs. By imposing a cost on emissions, the carbon price inflates operational savings available from the emission reduction activities. In particular, carbon price is considered one key way to capture opportunities available for reducing emissions from sectors.

\section{Verification}

GHG emission trades to date have included Verified Emission Reductions (VERs) (Springer \& Varilek, 2004). In essence, this represents quantifiable change in emissions whose outcomes from a particular activity can be verified by a third party. One of the key drivers to trade in the early stages of this is to hedge such risks (Convery \& Redmond, 2007). Prices of these transactions hold some information about prices in the future, because the trading of permits is likely to be valid in the first Kyoto commitment (Springer \& Varilek, 2004). However, there are serious doubts whether any particular reduction, regardless of how accurately quantified and monitored, will eventually earn a certificate in accordance with the rules of governments, which have not yet been developed (Heal, 2007; Tietenberg \& Nations, 1998). Thus, buyers are expected to have the lowest willingness to pay for pre-compatibility permits. In contrast, the restrictions imposed on binding emissions create a natural source of demand from companies who meet the restrictions internally. This would be expensive (Varilek \& Marenzi, 2001).

On the other hand, there is reason to wonder whether those price increases will be realised (Schmidheiny, 1992). This drives the private sector to find innovative ways and cost-effectiveness to abate emissions (Hoffman, 2005). Therefore, an effective MACC with actual and relevant data could help these firms and be the innovative driver.

Verifiable stakeholders could be located in seven main groups (Foster, Obbagy, \& Change, 2001; Rankin, Windsor, \& Wahyuni, 2011), firm employees and management, shareholders and owners, customers, government agencies, Non-Governmental Organisations (NGOs) and the general public, verifiers and GHG emission reduction trading partners and intermediaries.

To verify various anticipations depends on what the company intends to accomplish with information of its own emissions (Bellassen \& Leguet, 2007). The company can, however, want to use verification as a means to improve the inventory. If a company makes general obligations to reduce their emissions, then the company's verification has improved. (Assadourian, 2005; Foster et al., 2001). If a company intends to get some form of subsidy to reduce its emissions and is assured that it will not be punished in reducing emissions voluntarily, then verification expectations are greater. What a company want to achieve by keeping track of GHGs emissions, and thus the extent of activities achieved depends on the position of its administration, and can change over time (Kolk, 2009).

Current activities related to GHG emissions' verification fall into two main categories verification of emissions' inventories at firm level and verification of emissions' reduction projects (Foster et al., 2001; Vine \& Sathaye, 2000). In addition, methods used in these activities are similar in many ways as they examine both accuracy and completeness of reported emissions (Vine \& Sathaye, 2000). Therefore, both usually include baseline emissions and emissions over a period of monitoring.

Company-wide emissions' inventories require verification of a historical baseline if the company is committed to tracking or reducing their emissions relative to their last year, such as in 1990 (Springer \& Varilek, 2004). The first year, that the company used to estimate or measure emissions could be used as the base year. Any significant changes to the company's structure and actions would need to be modified, as well as any changes in methods used in calculating emissions. Any other changes affecting the image of GHGs would need to be included yearly (Foster et al., 2001). Changes may include a large company's acquisitions and divestitures, changes in product mix, outsourcing, and transfer of assets (Miozzo \& Grimshaw, 2011). If the company does not consider changes in its structure, it will use the base year emissions as the company's criterion for comparing between previous and current outcomes of any reduction in emissions.

Verification refers to collection of data to identify and prove environmental information, according to specific objectives, for example, to verify emissions of GHGs, emissions over the past year (Trexler \& Kosloff, 1998). Verification requires development and implementation of a strategy (PCA, 2002):

1- Scope of the data being verified (for example, GHG emissions from a company's operations in all parts of the 
world);

2- Types of data collection (for example, measurement of GHG emissions data, the level of activities causing emissions, and emission factors to translate activity data in to emissions of GHGs); and

3- Perform a battery of tests to make sure the information is correct (for example, to recalculate estimates of emissions).

Design and implementation of infrastructure at the level of the firm to gauge and report on GHG emissions is a relatively new and complex mission (Fiksel, McDaniel, \& Mendenhall, 1999). This measurement must be integrated and work in a firm's existing environmental management systems, leading to increased demand for human and financial resources (PCA, 2002). Measurement of GHGs also provides a technical challenge (Arroyo \& Peña, 2003; DeSimone \& Popoff, 2000). Although there are a growing number of consultants, engineers and accountants who can assist firms to develop a strategy for GHGs, there are only a few firms that have significant experience implementing these strategies (PCA, 2002).

It is important for companies to manage environmental strategies before agreeing to emissions trading. The companies involved need to build credibility in their Partnership for Climate Action (PCA) (Pattberg \& Stripple, 2008). Third party verification of emissions as a prerequisite to trading formulates a procedural situation that could impede market activity (Lieberman, Jonas, Nahorski, \& Nilsson, 2007). In addition, the use of third party auditors adds transaction costs for emissions trading, and there are currently no standards governing the adoption of auditors. The PCA (2002, p. 1) study, conducted in the USA on a group of firms was compiled by Environmental Defense, of which "intent is to increase understanding of GHG issues through an exploration of the basic and interconnected building blocks of a credible GHG management program". This analysis is based on identifying common elements and the core practices of capacity building programs for nine firms in a PCA. Every firm of the PCA independently and voluntarily designs its management of GHGs. A review of the each firm's program reveals its main elements, which can then be related and compared with a global framework designed program. These elements are setting goals, measuring emissions, action to reduce emissions, and accountability (Price, Galitsky, \& Kramer, 2008).

The PCA based its framework of evaluation on an organisation of the United States Acid Rain Program for sulphur dioxide emissions trading. The Acid Rain Program's design was used by the PCA to determine how to apply and control GHGs internationally and showed businesses how to start implementing their own programs for reduction in GHG emissions.

Further discussion with business of the Acid Rain Program revealed further information to benefit the emerging GHG programs by the PCA, both regulatory and voluntary. Firms in the PCA program, who wanted to follow regulatory and/or voluntary practice, used this information to design their individual frameworks. These frameworks represented the basic design decisions made by each firm in the design of their own approach to reduce emissions of GHGs. The details of each design highlighted the differences between each firm estimation and calculation of emission reduction.

Verification is significantly important for environmental data and may lead to actual worthwhile information (Ramanathan \& Xu, 2010). Quality control of emissions data commences with a solid basic foundation that is further supported by internal auditing, a process that is managed centrally by companies in the PCA. This process can be similar to a financial audit. It is a quality inspection during a second review by a third party verifier, which is increasingly being used by firms. Though all firms of PCA use or intend to use third-party verification, there are no uniform guidelines for conducting such reviews. In addition, the reviews are relatively new and there are few third-party auditors. However, those few, who have conducted public and private reviews, conclude that data management systems could develop greenhouse gas inventories. These inventories could then show more realistic estimates of the reduction in GHG emissions. This would confirm that the stock reflects accurate operations and covers the actual sources of material GHG emissions (Foster et al. 2001). These estimates and reductions would improve the firm's protocol and would have more consistency with the International Performance Measurement and Verification Protocol (IPMVP).

The International Performance Measurement and Verification Protocol (IPMVP) is an important tool to determine energy savings (Dietmair \& Verl, 2009). This method aims to increase certainty, reliability, and level of savings (AEPCA, 2004). It offers some options that determine savings (A, B, C, D). First of all, option (A) Retrofit Isolation (Key Parameter Measurement) which says that savings may be determined by field measurement of the key performance parameters. In fact, typical applications can contain a lighting retrofit, where the power drawn may be monitored and hours of operation are possible to be estimated. Option (B) Retrofit Isolation which says that all Parameter Measurement savings can be determined by field measurement of 
all key performance parameters that describe the energy use of the ECM-affected systems. Typical applications can contain a lighting retrofit where both power drawn and hours of operation are possible to be recorded. Another one is option C (Whole Facility) which sees that savings may be determined by measuring energy use at the whole facility or sub-facility level. Typical examples can consist of measurement of a facility where several ECMs may be implemented. Lastly, option (D) Calibrated Simulation which says that savings can be determined through simulation of the energy use of the whole facility. Typical applications can include measurement of a facility where several ECMs might be implemented. However historical energy data are not available. In line with the above discussion, it can be concluded that IPMVP is an appropriate tool for calculating and measuring energy saving (AEPCA, 2004; Energy \& Savings, 2001). Therefore, this study will calculate actual energy saving and GHG emission reductions by using the IPMVP, which will strengthen mechanisms for measuring, reporting and verification of emissions. IPMVP concentrates on the general aspects of every firm in all sectors. However, companies in specific sectors will need to calculate GHG inventories that are peculiar to their sector (Lazarowicz, 2009).

\section{Sectoral Analysis}

Studies by McKinsey and Company (2007a) have developed a MACC for the global economy and for different nations including Australia, the USA, UK, and Germany. National MACCs of this sort are necessarily at high levels, and concentrate on sectors of the economy. Overall, these MACCs disclose a common pattern of significantly available negative cost (net saving) of abatement opportunities (Enkvist et al., 2007). While these overall macro trends are generally instructive, national or sectoral MACCs are not particularly useful for decision making within particular industries and firms as well as for particular projects or investment decisions (Enkvist et al., 2007). However, MACCs related to firms in each sector may provide advantages (Vijay, DeCarolis, \& Srivastava, 2010). Sectoral analysis may require detailed disaggregation into many sectors. The total amount of global GHGs emissions across all sectors was 40,858 million tonnes of carbon dioxide equivalents $\left(\mathrm{Mt} \mathrm{CO}_{2} \mathrm{e}\right)$. Australia's net emissions across all sectors totalled $576.2\left(\mathrm{Mt} \mathrm{CO}_{2} \mathrm{e}\right)$ in 2008 (Library, 2010). In order to provide evidence, it is necessary that some issues related to each sector are reviewed.

Power sector (Stationery energy), in spite of the importance of the power sector and its contribution to the achievement of effective development programs, the sector's negative impacts on the environment include local effects on air, water, soil, as well as the emission of GHGs. This sector accounts for $25 \%$ of global GHG emissions that contribute to the phenomenon of climate change (Australia, 2007; Baumert, Herzog, \& Pershing, 2005). In addition, the sector has been shown to effect local air quality and public health (Economic \& Asia, 2001). The sector could provide the most significant abatement potential. Improving efficiency at generator plants, capturing and storing emissions, cogeneration, and renewable energy generation are some of the largest abatement potentials that are being investigated (EPAQ, 2008). Both households and industrial sectors consume energy, but the latter also emits GHGs from its processes. Thus, in Australia the power generation sector contributes $51.4 \%$ of GHGs emissions in $\mathrm{CO}_{2}$ equivalents (Library, 2010). Current emissions of $\mathrm{CO}_{2}$ from Australia grid-connected electricity generation sector are nearly 190 million tons per year with average emissions intensity of about 0.9 tons/MWhour ( $\mathrm{t} / \mathrm{MWh}$ ) (Chattopadhyay, 2010). Any abatement interventions here both in generation and consumption of energy could provide significant economic and environment benefits.

Industry sector emits about $21 \%$ of global GHG emissions (Australia 5.4\%) that includes direct fossil fuel combustion, indirect $\mathrm{CO}_{2}$ emissions from electricity and heat consumption, and non- $\mathrm{CO}_{2}$ emissions from industrial processes (Baumert et al., 2005). Many methods have been applied to measure pollution abatement costs, including surveys and econometric estimations (Riedy, 2003). The common study referenced is the USA cost data that comes from the Census Bureau's Pollution Abatement Costs and Expenditures (PACE) Survey (Shadbegian \& Gray, 2005). Another study has been conducted by McKinsey \& Company (2007) and underpinned by ten companies. This study attempts to identify abatement opportunities consisting of energy efficiency, shifting fuels, or shifting to low-carbon alternatives when building new infrastructure (Nauclér \& Enkvist, 2009).

Building sector can be split into residential and commercial, and accounts for $15.3 \%$ of international GHG emissions (Baumert et al., 2005). This is made up to $9.9 \%$ from commercial buildings and $5.4 \%$ for residential. The building sector represents a very small portion of the energy sector emissions and a slightly larger portion of the waste sector emissions. While there are a significant number of abatement options that are applicable to this sector, it represents a proportionally small amount of abatement gains. There is however a significant opportunity for the building sector to provide opportunities for improvements in construction practices that will result in emissions abatement in other sectors (EPAQ, 2008). For instance, improvements in more energy efficient 
buildings will result in a decrease in energy demand and consumption in most countries.

The United States and the European Union were the two largest emitters of carbon dioxide in 2004 (Baumert et al., 2005), with about $2 \mathrm{GtCO}_{2}$ and about $1.2 \mathrm{GtCO}_{2}$ emitted from each respectively. Emissions from the building sector varies greatly between countries, with a major association between emissions and the level of socioeconomic improvement in the region (Lazarowicz, 2009).

It is expected that emissions from buildings would be direct and indirect. These emissions are likely to grow from about $9 \mathrm{GtCO}_{2}$ in 2006 to $12 \mathrm{GtCO}_{2}$ in 2030, an increase of $40 \%$ between 2006 and 2030, which represents about $15 \%$ of the total increase in global emissions by 2030 (Lazarowicz, 2009; Perez-Lombard, Ortiz, \& Pout, 2008; Shiel, 2009). Non-OECD States are responsible for $88 \%$ of the total increase in emissions at world level; a new building in most of these areas in the coming decades will also be constructed. It is expected that non-OECD emissions from buildings will rise by $2.4 \%$ per year, while emissions in OECD states will rise by only $0.4 \%$ per year between 2006 and 2030 (Lazarowicz, 2009; Perez-Lombard et al., 2008).

Implementation of a carbon emission trading system is also high on the agenda of the Australian Government. The building sector is in favour of emission trading (for example, be able to trade emissions with other industries), and there is a feeling that this would be more effective (a gain in both monetary value and sustainability) for the industry. Energy consumption has increased in residential and commercial sectors and their services in Australia by 2.2\% in 2007-08 (Schultz, 2009). In 2005, commercial sector and services contributed to the $10 \%$ or $56 \mathrm{Mt} \mathrm{CO}_{2} \mathrm{e}$ from GHG emissions in Australian. The residential sector also increased emissions, though less rapidly, due to occupants' increasing use of such devices as energy-intensive air conditioning. In 2005 , the residential sector contributed $13 \%$ or $74 \mathrm{Mt} \mathrm{CO}_{2}$ e of GHGs in Australian emissions (McKnoulty, 2009). Figure 4 below illustrates the growth in the building sector's energy use during 1973-74 and 2003-04.

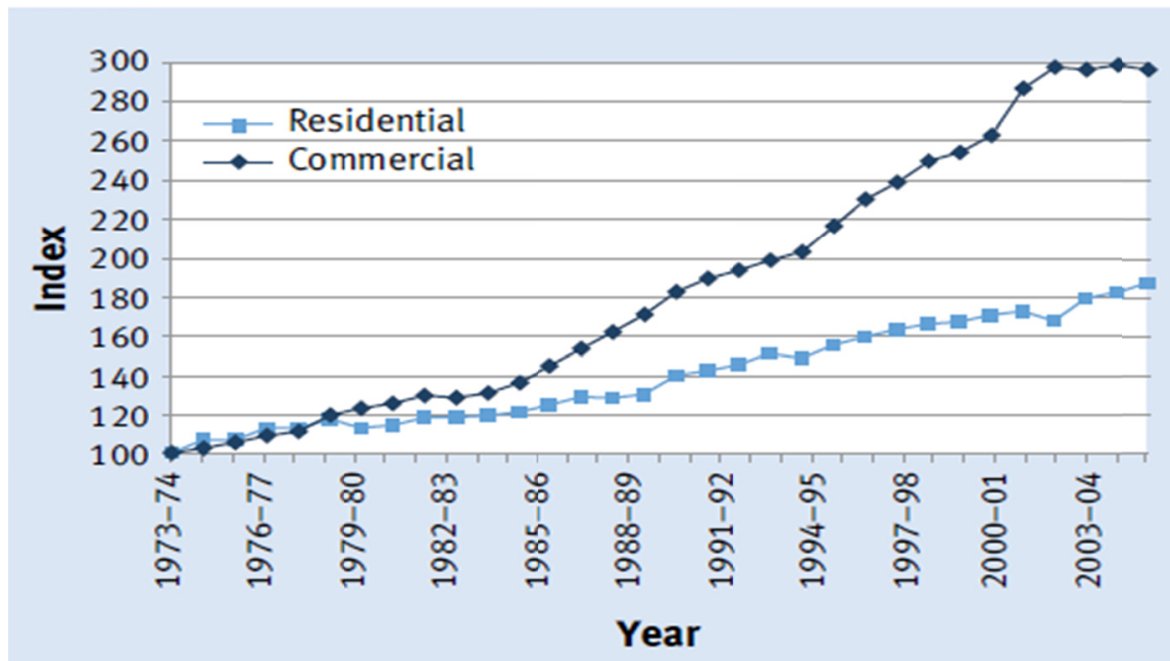

Figure 4. Growth in energy use in building sectors 1973-74 and 2003-04 (McKnoulty, 2009)

There are great opportunities to reduce (cost-effectively) GHG emissions from buildings (Shiel, 2009). It involves better insulated and designed buildings that create lower consumption of energy such as efficiency in lighting, lower heating and cooling energy demand, the replacement of gas with solar power and biomass in space and water heating, application of standards of efficiency in household appliances such as air-conditioners and the replacement of biomass for traditional cooking and heating gas in developing countries (ürge-Vorsatz, Harvey, Mirasgedis, \& Levine, 2007; Wagner et al., 2012). In addition, opportunities for mitigation increase, from behaviour changes to lowering energy consumption by users of buildings, particularly in developed countries and several sector of societies in advanced developing countries (Lazarowicz, 2009; Mark Levine \& Ürge-Vorsatz, 2008). Abatement cost curves of carbon reduction for the domestic sector show that some measures will be very effective in reducing emissions of $\mathrm{CO} 2$ and have demonstrated to be cost-effectiveness for different stakeholders (Kellett, 2007; Weiner, 2009). Therefore, the building sector could play a significant role in reducing GHG emissions with no cost/least cost abatement.

Agricultural sector activities account for approximately 15\% of global GHG emissions (Australia 15.2\%) (Baumert et al., 2005). This sector presents an important and unique opportunity to provide net negative 
emissions. Thus, the agricultural sector can offset emissions from other sectors. Within the literature there are many attempts to develop international MACCs for this sector (McKinsey, 2008, 2009; Moran et al., 2010). Specific MACCs have been developed for agriculture, employing qualitative judgment (Weiske, 2005, 2006), and other practical methods (Smith et al., 2008; Weiske et al., 2006). These studies are dominated by macroeconomic general equilibrium models for emissions reduction (top-down analysis). Committee on Climate Change (UK) has recognised the need to fulfill emission reductions in an economic way when it adopted a bottom-up MACC to make this method easier to apply (Moran et al., 2010).

The UK agriculture sector has used four methodological steps for developing a MACC (McVittie, Rees, \& Topp, 2010; Moran et al., 2010):

Identify the baseline business as usual (BAU) abatement emission projections for specified budgetary periods of near, medium and long term (e.g. 2012, 2017, 2022).

Identify potential additional abatement interventions for each period, above and beyond the abatement forecast in the BAU, by identifying an abatement measures inventory.

Quantify - calculate MACC

Qualify the maximum technical (abatement) potential MACC in terms of central, low and high estimates (accounting for uncertainties around estimates), based on a review of the likely levels of compliance/uptake associated with existing policies and alternative market conditions.

Transportation sector accounts for approximately 14\% of international (Australia 13.9\%) GHG emissions (Baumert et al., 2005). Many governments imposed taxes and raised prices of fuel to bring this sector in line with requirements of environmental standards. Existing technologies and changes in operational practices can be introduced to reduce energy consumption and thus emissions. These technical and operational measures have different degrees of $\mathrm{CO}_{2}$ emissions' reduction potential. Improvements in technologies have been considered the cornerstone for any abatement in the transportation sector, frequently providing end users with an economic benefit (Dinica, 2002; Li, Akintoye, Edwards, \& Hardcastle, 2005).

Increasing use of biofuels generates additional abatement costs. In road traffic (private cars), the most important technical lever is improving efficient consumption of both gasoline and diesel engines (McKinsey \& Company, 2008). Another important lever for fuel reduction is reducing vehicle weight. The forced introduction of hybrid vehicles in different classes could lead to considerable abatement. Enhancements in driving instruction offers the highest abatement approach across all parts of the mobility chain contributing further to GHG reductions such as traffic flow management and driving behaviour (Abe, 2011).

In aviation and rail traffic the benefits from technical optimization could improve abatement potentials and optimize capacity utilization. In the transportation sector, approximately $40 \%$ of abatement interventions pay off for decision makers (Baumert et al., 2005). However, they often require comparatively high initial investments.

Implementation of these levers in addition to the politically favoured use of biofuels (with additional abatement costs) could reduce emissions in the transportation sector by a total of $28 \mathrm{Mt} \mathrm{CO}_{2} \mathrm{e}$ by 2020 globally (Baumert et al., 2005). This reduction corresponds to an $11 \%$ decrease compared to today's level. McKinley \& Company (2007) joint work with automobile makers proposes that these measures might reduce average fuel consumption per kilometre by more than $50 \%$ with net economic benefits to consumers. This could result in a net savings of $1.1 \mathrm{Mt} \mathrm{CO}_{2} \mathrm{e}$ per annum if a quarter of new cars reached this standard by 2030 . Thus, further studies are needed at firm level to test various methods, models, and assumptions of MACCs developed for national and global analyse. Therefore, ways to reduce GHGs while maintaining a sustainable economy need to be found and implemented.

\section{Conclusion}

Decision-makers and stockholders are looking for how to determining the cost and benefits of reducing GHG emissions and they need to understand estimate environmental costs to reduction emissions. Many research into this topic have been conducted in last few decades and report different results. The reason why is studies that assumptions used for estimating MACCs are different. The results of this study confirm the notion that actual data is important to build MACCs. Overall, while there have been developments made in applying approaches of MACCs, much remains to be done in future.

\section{References}

Abe, M. (2011). Achieving a sustainable automotive sector in Asia and the Pacific: Challenges and opportunities for the reduction of vehicle $\mathrm{CO}_{2}$ emissions. Asia-Pacific Research and Training Network on Trade Working 
Paper Series, No. 108.

AEPCA. (2004). A Best Practice Guide to Measurement and Verification of Energy Savings (T. A. E. P. C. A. f. the, I. A. P. o. A. i. the \& A. D. o. I. T. a. Resources, Trans.). Commonwealth of Australia.

Aldy, J. E., \& Stavins, R. (2012). The Promise and Problems of Pricing Carbon: Theory and Experience. Journal of Environment \& Development, 21(2), 152-180. http://dx.doi.org/10.1177/1070496512442508

Anger, N. (2008). Emissions trading beyond Europe: Linking schemes in a post-Kyoto world. Energy Economics, 30(4), 2028-2049.

Arroyo, V., \& Peña, N. (2003). Establishing A Domestic GHG Reduction Target: Key Approaches AND Challenges. A Climate Policy Framework: Balancing Policy and Politics, 29.

Assadourian, E. (2005). State of Corporate Responsibility and the Environment. The Geo. Int'l Envtl. L. Rev., 18, 571.

Australia, B. C. O. F. (2007). Strategic framework to reduce emissions.

Bailie, A., Bernow, S., Dougherty, W., \& Goldberg, M. (2009). The Bottom Line on Kyoto. World Wildlife Fund (WWF).

Bataille, C., Jaccard, M., Nyboer, J., \& Rivers, N. (2006). Towards general equilibrium in a technology-rich model with empirically estimated behavioral parameters. The Energy Journal, Special Issue\# 2, 93-112.

Baumert, K., Herzog, T., \& Pershing, J. (2005). Navigating the numbers: Greenhouse gas data and international climate policy. The World Resources Institute, $10 \mathrm{G}$ Street, NE Suite 800 Washington, D. C. 20002 USA.

Bellassen, V., \& Leguet, B. (2007). The emergence of voluntary carbon offsetting. Renewable energy, 20, 5.

Bohringer, C., \& Loschel, A. (2006). Promoting renewable energy in Europe: a hybrid computable general equilibrium approach. The Energy Journal, Special Issue\# 2, 135-150.

Böhringer, C., \& Rutherford, T. F. (2008). Combining bottom-up and top-down. Energy Economics, 30(2), 574-596.

Chattopadhyay, D. (2010). Modeling greenhouse gas reduction from the Australian electricity sector. Power Systems, IEEE Transactions on, 25(2), 729-740.

Convery, F. J., \& Redmond, L. (2007). Market and price developments in the European Union emissions trading scheme. Review of Environmental Economics and Policy, 1(1), 88-111.

Criqui, P., Mima, S., \& Viguier, L. (1999). Marginal abatement costs of $\mathrm{CO}_{2}$ emission reductions, geographical flexibility and concrete ceilings: an assessment using the POLES model. Energy policy, 27(10), 585-601.

De Vries, B. J. M., van Vuuren, D. P., \& Hoogwijk, M. M. (2007). Renewable energy sources: Their global potential for the first-half of the 21st century at a global level: An integrated approach. Energy policy, 35(4), 2590-2610. http://dx.doi.org/10.1016/j.enpol.2006.09.002

DECC. (2009). Carbon Valuation in UK Policy Appraisal: A Revised Approach: Climate Change Economics. Department of Energy and Climate Change,UK.

DEFRA. (2003). The Scientific Case for Setting a Long Term Emissions Reduction Target, UK Department for Environment, Food and Regional Affairs, London. Retrieved 30 May 2012 from http://www.defra.gov.uk/environment/climatechange/pubs

DeSimone, L. D., \& Popoff, F. (2000). Eco-efficiency: The business link to sustainable development. The MIT Press.

Dietmair, A., \& Verl, A. (2009). Energy consumption forecasting and optimisation for tool machines. Energy, $62 / 63$.

Dinica, V. (2002). Energy policies for $\mathrm{CO}_{2}$ emission reduction. Encyclopedia of life support systems.

Economic, U. N., \& Asia, S. C. f. W. (2001). Towards Harmonization of Environmental Standards in the Energy Sector of ESCWA Member States. United Nations.

Ekins, P., Kesicki, F., \& Smith, A. Z. P. (2011). Marginal Abatement Cost Curve: A call for caution. UCL Energy Institute \& University College Londone, UK.

Ellerman, A., \& Decaux, A. (1998). Analysis of post-Kyoto $\mathrm{CO}_{2}$ emissions trading using marginal abatement curves. 
Energy, D., \& Savings, W. (2001). International Performance Measurement \& Verification Protocol.

Enkvist, P., Nauclér, T., \& Rosander, J. (2007). A cost curve for greenhouse gas reduction. McKinsey Quarterly, 1,34 .

EPAQ. (2008). Environmental Protection Agency - Queensland An enhanced Queensland Marginal Abatement Cost Curve. Retrieved from http://www.google.com.au/

Faber, J., Nelissen, D., St Amand, D., Consulting, N., Balon, T., Baylor, M., . . Kane, D. (2011). Marginal Abatement Costs and Cost Effectiveness of Energy-Efficiency Measures.

Fiksel, J., McDaniel, J., \& Mendenhall, C. (1999). Measuring progress towards sustainability principles, process and best practices.

Flachsland, C., Brunner, S., Edenhofer, O., \& Creutzig, F. (2011). Climate policies for road transport revisited (II): Closing the policy gap with cap-and-trade. Energy policy.

Foster, S. A., Obbagy, J. E., \& Change, P. C. O. G. C. (2001). An Overview of Greenhouse Gas Emissions Verification Issues. Pew Center on Global Climate Change.

Gallaher, M. P., Morgan, C. L., \& Shadbegian, R. J. (2008). Redesign of the 2005 pollution abatement costs and expenditure survey. Journal of Economic and Social Measurement, 33(4), 309-360.

Garnaut, R. (2008). The Garnaut climate change review. change, 13, 1-5.

Grubb, M., Köhler, J., \& Anderson, D. (2002). Induced technical change in energy and environmental modeling: Analytic approaches and policy implications. Annual Review of Energy and the Environment, 27(1), 271-308. http://dx.doi.org/10.1146/annurev.energy.27.122001.083408

Guo, J., Hepburn, C. J., Tol, R. S. J., \& Anthoff, D. (2006). Discounting and the social cost of carbon: a closer look at uncertainty. environmental science \& policy, 9(3), 205-216. http://dx.doi.org/10.1016/j.envsci.2005.11.010

Hamilton, K., Bayon, R., Turner, G., \& Higgins, D. (2007). State of the voluntary carbon markets 2007. Picking up steam. Washington, DC.

Hanley, N. (1992). Are there environmental limits to cost benefit analysis? Environmental and Resource Economics, 2(1), 33-59.

Hardisty. (2009). Analysing the role of decision-making economics for industry in the climate change era. Management of Environmental Quality: An International Journal, 20(2), 205-218. http://dx.doi.org/10.1108/14777830910939507

Heal, G. (2007). A celebration of environmental and resource economics. Review of Environmental Economics and Policy, 1(1), 7-25. http://dx.doi.org/ 10.1093/reep/rem007

Hepburn, C., \& Stern, N. (2008). A new global deal on climate change. Oxford Review of Economic Policy, 24(2), 259-279. http://dx.doi.org/ 10.1093/oxrep/grn020

Hoffman, A. J. (2005). Climate change strategy: The business logic behind voluntary greenhouse gas reductions. California Management Review, 47(3), 21-46.

Hogg, D., Ballinger, A., \& Elliot, T. (2008). Development of Marginal Abatement Cost Curves for the Waste Sector (e. r. c. Committee on Climate Change. Bristol, Trans.) (pp. 1-199).

Hutton, G., Haller, L., \& Bartram, J. (2007). Global cost-benefit analysis of water supply and sanitation interventions. Journal of water and health, 5(4), 481-502. http://dx.doi.org/ 10.2166/wh.2007.009

International Energy Agency. (2007). World energy outlook, IEA, Paris.

IPCC. (2007). Fourth Assessment Report, Impacts, Adaptation and Vulnerability, Intergovernmental Panel on Climate Change. Cambridge: Cambridge University Press.

Jaccard, M., Nyboer, J., Bataille, C., \& Sadownik, B. (2003). Modeling the cost of climate policy: distinguishing between alternative cost definitions and long-run cost dynamics. Energy Journal, 24(1), 49-73.

Jackson, T. (1991). Least-cost greenhouse planning supply curves for global warming abatement. Energy policy, 19(1), 35-46.

Jakob, M. (2006). Marginal costs and co-benefits of energy efficiency investments: The case of the Swiss residential sector. Energy policy, 34(2), 172-187. 
Jorge, F. P., Genice, A., \& M. O. (2005). $\mathrm{SO}_{2}$, NOx, and Particle Control Technologies and Abatement Costs for the Mexican Electricity Sector. Centre for Energy Research (CIE), UNAM, México World Resources Institute (WRI). Secretaría de Energía (SENER).

Jotzo, F., \& Betz, R. (2009). Australia's emissions trading scheme: opportunities and obstacles for linking. Climate Policy, 9(4), 402-414. http://dx.doi.org/10.3763/cpol.2009.0624

Kanudia, A., \& Loulou, R. (1999). Advanced bottom-up modelling for national and regional energy planning in response to climate change. International Journal of Environment and Pollution, 12(2), 191-216.

Kellett, D. J. (2007). Community-based energy policy: a practical approach to carbon reduction. Journal of environmental planning and management, 50(3), 381-396. http://dx.doi.org/10.1080/09640560701261679

Kesicki, F. (2010a). Marginal abatement cost curves for policy making-expert-based vs. model-derived curves. Paper presented at the IAEE's 2010 International Conference, Rio de Janeiro.

Kesicki, F. (2010b). Marginal Abatement Cost Curves for Policy Making-Expert-Based vs. Model-Derived Curves (pp. 1-19). London WC1H 0HY, United Kingdom, viewed 24 February 2011.

Kesicki, F. (2010c). Marginal Abatement Cost Curves: Combining Energy System Modelling and Decomposition Analysis. Environmental Modeling and Assessment, 1-11.

Kesicki, F., \& Strachan, N. (2011). Marginal abatement cost (MAC) curves: confronting theory and practice. Environmental science \& policy. http://dx.doi.org/10.1016/j.envsci.2011.08.004

Klepper, G., \& Peterson, S. (2004). Marginal abatement cost curves in general equilibrium: the influence of world energy prices. Working Papers.

Kockelman, K., Bomberg, M., Thompson, M., Whitehead, C., \& Traveled, V. M. (2009). GHG Emissions Control Options. The University of Texas at Austin-white paper.

Kolk, A. (2009). International business and global climate change. Routledge.

Kuik, O., Brander, L., \& Tol, R. (2009). Marginal abatement costs of greenhouse gas emissions: A meta-analysis. Energy Policy, 37(4), 1395-1403.

Kuwahata, R., \& Monroy, C. R. (2011). Market stimulation of renewable-based power generation in Australia. Renewable and Sustainable Energy Reviews, 15(1), 534-543. http://dx.doi.org/10.1016/j.rser.2010.08.020

Lazarowicz, M. (2009). Global Carbon Trading: a framework for reducing emissions. Stationery Office.

Lee, H., Zhou, D., Jung, Y., Wisniewski, J., \& Sathaye, J. (1996). Greenhouse gas emissions inventory and mitigation strategies for asian and pacific countries: Summary of workshop presentations and working group discussions. Ambio, 220-228.

Legge, T., \& Scott, S. (2009). Policy Options to Reduce Ireland's Greenhouse Gas Emissions. Esri.

Li, B., Akintoye, A., Edwards, P. J., \& Hardcastle, C. (2005). Perceptions of positive and negative factors influencing the attractiveness of PPP/PFI procurement for construction projects in the UK: Findings from a questionnaire survey. Engineering, Construction and Architectural Management, 12(2), 125-148. http://dx.doi.org/10.1108/09699980510584485

Library, P. (2010). How much Australia emits. Retrieved 12 February 2011 from http://www.aph.gov.au/library/pubs/climatechange/

Lieberman, D., Jonas, M., Nahorski, Z., \& Nilsson, S. (2007). Accounting for climate change: uncertainty in greenhouse gas inventories-verification, compliance, and trading. Springer Verlag.

Löschel, A. (2002). Technological change in economic models of environmental policy: a survey. Ecological Economics, 43(2-3), 105-126.

Markets, O. o. G. a. E. (2010). The Renewable Obligation Buy-out Price and Mutualisation Ceiling.

McKinsey, \& Company (Cartographer). (2008). Costs and potentials of greenhouse gas abatement in the Czech Republic- Key findings. Retrieved from http://lightbucket.wordpress.com/2008/05/17/the-cost-of-carbon-abatement/

McKinsey. (2008). An Australian cost curve for greenhouse gas reduction (p. 28). Sydney: McKinsey \& Company Australi Climate Change Initiative.

McKinsey. (2009). Pathways to a low-carbon economy - global greenhouse gases (GHG) abatement cost curve. In J. Edmonds (Ed.), Version 2 of the Global Greenhouse Gas Abatement Cost Curve - January 2009. (p. 
192). United States: Climate Change Special Initiative.

McKitrick, R. (1999). A derivation of the marginal abatement cost curve. Journal of Environmental Economics and Management, 37(3), 306-314.

McKnoulty, J. (2009). Building ClimateSmart in Queensland Building and Regulatory Reform. Published by the Queensland Government.

McVittie, A. B., Rees, R., \& Topp, C. F. E. (2010). Marginal abatement cost curves for UK agricultural greenhouse gas emissions. Universität Hohenheim, Stuttgart, Germany, 33.

Metcalf, G. E. (2009). Designing a carbon tax to reduce US greenhouse gas emissions. Review of Environmental Economics and Policy, 3(1), 63-83.

Metcalfe, J. S. (1995). Technology systems and technology policy in an evolutionary framework. Cambridge Journal of Economics, 19(1), 25-46.

Miozzo, M., \& Grimshaw, D. (2011). Capabilities of large services outsourcing firms: the "outsourcing plus staff transfer model" in EDS and IBM. Industrial and Corporate Change, 20(3), 909-940.

Moran, D., Macleod, M., Wall, E., Eory, V., McVittie, A., Barnes, A., . . Moxey, A. (2010). Marginal Abatement Cost Curves for UK Agricultural Greenhouse Gas Emissions. Journal of Agricultural Economics, 62(1). Retrieved from http://onlinelibrary.wiley.com/doi/10.1111/j.1477-9552.2010.00268

Morris, J., Paltsev, S., \& Reilly, J. (2008). Marginal abatement costs and marginal welfare costs for greenhouse gas emissions reductions: results from the EPPA model. Environmental Modeling and Assessment, 1-12.

Morris, S., Goldstein, G., \& Fthenakis, V. (2002). NEMS and MARKAL-MACRO models for energy-environmental-economic analysis: A comparison of the electricity and carbon reduction projections. Environmental Modeling and Assessment, 7(3), 207-216.

Moss, R., Edmonds, J., Hibbard, K., Manning, M., Rose, S., van Vuuren, D., . . Kram, T. (2010). The next generation of scenarios for climate change research and assessment. Nature, 463(7282), 747-756.

Murphy, R., \& Jaccard, M. (2011). Energy efficiency and the cost of GHG abatement: A comparison of bottom-up and hybrid models for the US. Energy policy. http://dx.doi.org/10.1016/j.enpol.2011.08.033

Murphy, R., Rivers, N., \& Jaccard, M. (2007). Hybrid modeling of industrial energy consumption and greenhouse gas emissions with an application to Canada. Energy Economics, 29(4), 826-846. http://dx.doi.org/10.1016/j.eneco.2007.01.006

Nauclér, T., \& Enkvist, P. A. (2009). Pathways to a low-carbon economy: Version 2 of the global greenhouse gas abatement cost curve. McKinsey \& Company, 26-31.

Nordhaus, W. D., \& Yang, Z. (1996). A regional dynamic general-equilibrium model of alternative climate-change strategies. The American Economic Review, 741-765.

Nystrom, I., \& Wene, C. O. (1999). Energy-economy linking in MARKAL-MACRO: interplay of nuclear, conservation and CO 2 policies in Sweden. International Journal of Environment and Pollution, 12(2), 323-342.

Parker, L. (2009). Climate change and the EU Emissions trading Scheme (ETS): Kyoto and Beyond. International Journal of Energy, Environment and Economics, 17(4), 385.

Pattberg, P., \& Stripple, J. (2008). Beyond the public and private divide: remapping transnational climate governance in the 21st century. International Environmental Agreements: Politics, Law and Economics, 8(4), 367-388. http://dx.doi.org/ 10.1007/s10784-008-9085-3

PCA. (2002). Common Elements among Advanced Greenhouse Gas Management Programs. The Partnership for Climate Action. Retrieved 7 July 2012 from http://www.greenbiz.com

Perez-Lombard, L., Ortiz, J., \& Pout, C. (2008). A review on buildings energy consumption information. Energy and buildings, 40(3), 394-398. http://dx.doi.org/10.1016/j.enbuild.2007.03.007

Powell, J. B. (2011). Future energy and chemicals from bio-based feed stocks: catalytic challenges and opportunities. Shell Chief Scientist -Chemical Engineering. University of Delaware Campus, Newark, DE.

Price, L., Galitsky, C., \& Kramer, K. J. (2008). International experience with key program elements of industrial energy efficiency or greenhouse gas emissions reduction target-setting programs.

Pye, S., Fletcher, K., Gardiner, A., Angelini, T., Greenleaf, J., Wiley, T., \& Haydock, H. (2008). Review and 
update of UK abatement costs curves for the industrial, domestic and non-domestic sectors 1-137.

Ramanathan, V., \& Xu, Y. (2010). The Copenhagen Accord for limiting global warming: Criteria, constraints, and available avenues. Proceedings of the National Academy of Sciences, 107(18), 8055.

Rankin, M., Windsor, C., \& Wahyuni, D. (2011). An investigation of voluntary corporate greenhouse gas emissions reporting in a market governance system: Australian evidence. Accounting, Auditing \& Accountability Journal, 24(8), 1037-1070. http://dx.doi.org/ 10.1108/09513571111184751

Riedy, C. (2003). A Framework for Economic Analysis of Greenhouse Abatement Options. Retrieved 20 September 2010 from http://een.anu.edu.au/wsprgpap/papers/riedy1

Rivers, N., \& Jaccard, M. (2006). Useful models for simulating policies to induce technological change. Energy policy, 34(15), 2038-2047.

Sandor, R. L., Bettelheim, E. C., \& Swingland, I. R. (2002). An overview of a free-market approach to climate change and conservation. Philosophical Transactions of the Royal Society of London. Series A: Mathematical, Physical and Engineering Sciences, 360(1797), 1607-1620. http://dx.doi.org/10.1098/rsta.2002.1022

Scarborough, H. (2011). Intergenerational equity and the social discount rate. Australian Journal of Agricultural and Resource Economics, 55(2), 145-158. http://dx.doi.org/ 10.1111/j.1467-8489.2011.00532.x

Schaefer, A., \& Jacoby, H. D. (2005). Technology detail in a multisector CGE model: transport under climate policy. Energy Economics, 27(1), 1-24.

Schafer, A., \& Jacoby, H. D. (2006). Experiments with a hybrid CGE-MARKAL model. The Energy Journal, Special Issue\# 2, 171-177.

Schmidheiny, S. (1992). Changing course: A global business perspective on development and the environment. the MIT Press.

Schultz, A. (2009). Energy update 2009, Australian Bureau of Agricultural and Resource Economics, Canberra.

Schwarzenegger, A. (2005). Emission reduction opportunities for non-CO2 greenhouse gases in California. California: California Climate Change Center.

Seebregts, A. J., Goldstein, G. A., \& Smekens, K. (2001). Energy/environmental modeling with the MARKAL family of models.

Shadbegian, R. J., \& Gray, W. B. (2005). Pollution abatement expenditures and plant-level productivity: A production function approach. Ecological Economics, 54(2-3), 196-208.

Shiel, J. (2009). Practical greenhouse gas reduction strategies for the existing building stock. Architectural Science Review, 52(4), 270-278. http://dx.doi.org/10.3763/asre.2009.0070

Shobe, W., \& Burtraw, D. (2012). Rethinking environmental federalism in a warming world. Resources for the Future Discussion Paper (pp. 12-04).

Smale, R., Hartley, M., Hepburn, C., Ward, J., \& Grubb, M. (2006). The impact of CO2 emissions trading on firm profits and market prices. Climate Policy, 6(1), 31-48. http://dx.doi.org/10.1080/14693062.2006.9685587

Smith, P., Martino, D., Cai, Z., Gwary, D., Janzen, H., Kumar, P., . . Rice, C. (2007). Policy and technological constraints to implementation of greenhouse gas mitigation options in agriculture. Agriculture, Ecosystems \& Environment, 118(1-4), 6-28.

Smith, P., Martino, D., Cai, Z., Gwary, D., Janzen, H., Kumar, P., . . Rice, C. (2008). Greenhouse gas mitigation in agriculture. Philosophical Transactions of the Royal Society B: Biological Sciences, 363(1492), 789.

Speth, J. G. (2009). The bridge at the edge of the world: Capitalism, the environment, and crossing from crisis to sustainability. Yale University Press.

Springer, U., \& Varilek, M. (2004). Estimating the price of tradable permits for greenhouse gas emissions in 2008-12. Energy policy, 32(5), 611-621. http://dx.doi.org/10.1016/S0301-4215(02)00313-0

Stankeviciute, L., Kitous, A., \& Criqui, P. (2008). The fundamentals of the future international emissions trading system. Energy policy, 36(11), 4272-4286.

Stavins, R. N. (2007). Environmental economics: National Bureau of Economic Research.

Stern, N. (2008). The economics of climate change. The American Economic Review, 98(2), 1-37. 
Stern, N. H. (2007). The economics of climate change: the Stern review. Cambridge Univ Pr.

Sullivan, A., \& Sheffrin, S. M. (2003). Economics: Principles in action. Upper Saddle River, New Jersey, 7458, 90.

Sweeney, J., \& Weyant, J. (2008). Analysis of Measures to Meet the Requirements of California's Assembly Bill 32. Discussion draft, September 2008 (p. 108). California, viewed 15 April 2012: Stanford, CA: Stanford University Precourt Institute for Energy Efficiency.

Tester, J. W. (2005). Sustainable energy: choosing among options. The MIT Press.

Tietenberg, T., \& Nations, U. (1998). International Rules for Greenhouse Gas Emissions: Defining the Principles, Modalities, Rules and Guidelines for Verification, Reporting and Accountabiligy. Executive Summary. United Nations.

Trexler, M. C., \& Kosloff, L. H. (1998). The 1997 Kyoto Protocol: what does it mean for project-based climate change mitigation? Mitigation and Adaptation Strategies for Global Change, 3(1), 1-58.

Turner, G., Sjardin, M., \& Capua, M. D. (2010). US Marginal Abatement Cost Curve, 1-33. Retrieved from http://en.wikipedia.org/wiki/Marginal_Abatement_Cost\#cite_ref-1

UN. (2003). Integrated Environmental and Economic Accounting. New York: United Nation.

ürge-Vorsatz, D., Harvey, L. D. D., Mirasgedis, S., \& Levine, M. D. (2007). Mitigating CO2 emissions from energy use in the world's buildings. Building research \& information, 35(4), 379-398.

van Odijk, S., Mol, S., Harmsen, R., Struker, A., \& Jacobs, E. (2012). Utilizing marginal abatement cost curves (MAC curves) to strategically plan CO2 reduction possibilities for the water sector: the case of watercycle organisation Waternet.

Van Vuuren, D., Meinshausen, M., Plattner, G., Joos, F., Strassmann, K., Smith, S., . . . De La Chesnaye, F. (2008). Temperature increase of 21 st century mitigation scenarios. Proceedings of the National Academy of Sciences, 105(40), 15258.

Varilek, M., \& Marenzi, N. (2001). Greenhouse Gas Price Scenarios for 2000-2012: Impact of Different Policy Regimes. Washington, DC: Natsource LLC.

Vijay, S., DeCarolis, J. F., \& Srivastava, R. K. (2010). A bottom-up method to develop pollution abatement cost

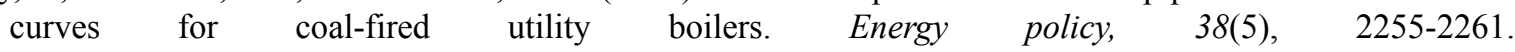
http://dx.doi.org/10.1016/j.enpol.2009.12.013

Vine, E. L., \& Sathaye, J. A. (2000). The monitoring, evaluation, reporting, verification, and certification of energy-efficiency projects. Mitigation and Adaptation Strategies for Global Change, 5(2), 189-216.

Wagner, F., Amann, M., Borken-Kleefeld, J., Cofala, J., Höglund-Isaksson, L., Purohit, P., . . Winiwarter, W. (2012). Sectoral marginal abatement cost curves: implications for mitigation pledges and air pollution co-benefits for Annex I countries. Sustainability Science, 1-16. http://dx.doi.org/10.1007/s11625-012-0167-3

Wang, K., Wang, C., \& Chen, J. (2009). Analysis of the economic impact of different Chinese climate policy options based on a CGE model incorporating endogenous technological change. Energy policy, 37(8), 2930-2940. http://dx.doi.org/10.1016/j.enpol.2009.03.023

Wassmann, R., \& Pathak, H. (2007). Introducing greenhouse gas mitigation as a development objective in rice-based agriculture: II. Cost-benefit assessment for different technologies, regions and scales. Agricultural Systems, 94(3), 826-840.

Watkiss, P., \& Hunt, A. (2011). Cover Delivery Report.

Weiner, M. (2009). Energy Use in Buildings and Industry: Technical Appendix. London, Committee on Climate Change.

Weiske, A. (2005). Survey of technical and management-based mitigation measures in agriculture. MEACAP WP3 D7a, 146.

Weiske, A. (2006). Selection and specification of technical and management-based greenhouse gas mitigation measures in agricultural production for modelling. MEACAP WP3 D10a, 71.

Weiske, A., Vabitsch, A., Olesen, J. E., Schelde, K., Michel, J., Friedrich, R., \& Kaltschmitt, M. (2006). Mitigation of greenhouse gas emissions in European conventional and organic dairy farming. Agriculture, 
Ecosystems \& Environment, 112(2-3), 221-232.

Wilkinson, P., Smith, K. R., Davies, M., Adair, H., Armstrong, B. G., Barrett, M., . . Oreszczyn, T. (2009). Public health benefits of strategies to reduce greenhouse-gas emissions: household energy. The Lancet, 374(9705), 1917-1929. http://dx.doi.org/10.1016/S0140- 6736(09)61713-X

Worrell, E., Ramesohl, S., \& Boyd, G. (2004). Advances in Energy Forecasting Models Based on Engineering

$\begin{array}{lccc}\text { Economics. } & \text { Annu. } & \text { Rev. } & \text { Environ. } \\ \mathrm{http} / / / \mathrm{dx} \text {.doi.org/10.1146/annurev.energy.29.062403.102042 }\end{array}$ 